\title{
Isolation of intimal endothelial cells from the human thoracic aorta: Study protocol
}

\author{
Adeleh Poursaleh ${ }^{1}$, Golnaz Esfandiari ${ }^{1}$, Farahnaz Sadegh Beigee ${ }^{2}$, Nahal Eshghifar ${ }^{3}$, \\ Mohammad Najafi*4,1
}

Received: 8 Aug 2018

Published: 4 Jun 2019

\begin{abstract}
Background: Vessel endothelial cells are extensively applied to study the mechanism of atherosclerosis. Some cellular sources including human umbilical artery endothelial cells (HUAECs) and human umbilical vein endothelial cells (HUVECs) are mostly applied in the experimental studies. We described a method for isolating the human endothelial cells from the human thoracic aorta.

Methods: Normal aortic samples were prepared from subjects with brain death in Masih Daneshvari Hospital. The endothelial cells were isolated using collagenase and were evaluated by the measurement of CD31 marker. Furthermore, the digestion efficacy was studied by vessel histological analysis, and the adhesion mechanism was investigated by leukocyte endothelial adhesion assay kit.

Results and Conclusion: The isolation protocol is found as a fast and simple technique with a proper cellular load to separate the endothelial cells from the human aorta.
\end{abstract}

Keywords: Human aortic endothelial cell, Cell isolation, Protocol

Conflicts of Interest: None declared

Funding: Iran University of Medical Sciences

\section{${ }^{*}$ This work has been published under CC BY-NC-SA 1.0 license. \\ Copyright $\odot$ Iran University of Medical Sciences}

Cite this article as: Poursaleh A, Esfandiari G, Sadegh Beigee F, Eshghifar N, Najafi M. Isolation of intimal endothelial cells from the human thoracic aorta: Study protocol. Med J Islam Repub Iran. 2019 (4 Jun);33:51. https://doi.org/10.47176/mjiri.33.51

\section{Introduction}

The aorta is the first and largest arterial segment directly connected to the heart and is an expandable reservoir for multiple vital functions. Physiologically, it is a high-risk section for the development of stenosis (1). The function of the aorta is associated with the wall structure; the intima, media, and adventitia (2). The intima is originated from the endothelium, a thin layer of endothelial cells, sub-endothelial connective tissue and internal elastic lamina. Media contains a protein network of elastin-enriched collagen, fibroblasts, and vascular smooth muscle cells. (3) Adventitia, the outer protecting layer of the media, includes connective tissue and fibroblasts. The endothelium creates a semi-infiltrative barrier between the blood and surrounding tissues and, controls the permeability of cells (4). Endothelial cells (ECs) are related by tight junctions and would lead to the vascular homeostasis, thrombosis, fibrinolysis, vascular tone, tumorigenesis, and

Corresponding author: Dr Mohammad Najafi, nbsmmsbn@iums.ac.ir

1. Biochemistry Department, Iran University of Medical Sciences, Tehran, Iran

2. Shahid Beheshti University of Medical Sciences, Masih Daneshvari Hospital, Tehran, Iran

3. Department of Cellular and Molecular biology, Faculty of Advanced Science and Technology, Tehran Medical Sciences, Islamic Azad University, Tehran, Iran

4. Cellular and Molecular Research Center; Biochemistry Department, Firoozabadi Hospital, Iran University of Medical Sciences, Tehran, Iran blood-borne cell adhesion. Furthermore, the endothelial cells relate to the para-cellular pathways and leukocyte rolling process, are involved in metabolic activities and can be activated by a number of circulating agents such as amines, nucleotides, lipoproteins, and reactive oxygen species (5) . In addition, inflammatory conditions and the activation of endothelial cells by chemokines lead to the expression of adhesion proteins.

As a result, endothelial cells have been applied as a primary cellular source to study the physiological and pathophysiological processes of various vascular diseases (6). The endothelial cell sources are isolated from the human arteries and vein umbilical cords. Several methods were designed and developed for the separation of endothelial cells from human arteries (7). In this study, we modified the isolation method of the intimal endothelial cells from the human thoracic aorta. In addition, we stud-

\section{$\uparrow$ What is "already known" in this topic:}

The endothelial cell sources are isolated from the human artery and vein umbilical cords.

\section{$\rightarrow$ What this article adds:}

A modified method is suggested to isolate the endothelial cells from human aorta. 
ied the adhesion process between endothelial cells and leukocytes.

\section{Methods}

\section{Study design and Setting}

Endothelial cells were isolated from the human normal aortic segments. The cellular isolation was evaluated using histology, CD31 marker and adhesion processes.

\section{Tissue Sample and Ethical Approval}

Normal aortic samples were prepared from subjects with brain death from transplant Organ Procurement Unit (OPU) center of Masih Daneshvari Hospital. The samples were placed in saline/amphotericin B/gentamicin/ PenStrep $(0.25 \mu \mathrm{g} / \mathrm{ml}, 50 \mathrm{mg} / \mathrm{ml}$ and $\% 6$, respectively) (8) and were transferred into the laboratory of Biochemistry department (IUMS) in safe conditions. The University Ethics Committee approved the study (93-03-30-25069).

\section{Procedure}

1. Preparation of Collagenase

1. Mix PBS buffer (Phosphate-buffered saline, $5 \mathrm{ml}$ ) with collagenase D (10 mg) (Cat. No.: C5138-100MG; Sigma Aldrich).

2. Perform the sterile filtration process (filter, $0.2 \mu \mathrm{m}$ ) then, store the collagenase solution at $4{ }^{\circ} \mathrm{C}$.

\section{Preparation of Endothelium Cell Medium}

1. Prepare Endothelial Cell Growth Medium MV for freshly consumption (Cat. No.: C-22022-500ml; PromoCell) (7) containing endothelial cell growth complement, ECGS / H $0.004 \mathrm{ml} / \mathrm{ml}$, hEGF-5 $50 \mu \mathrm{g} / 500 \mu \mathrm{l}$,
HC-500 $500 \mu \mathrm{g} / 500 \mu \mathrm{l}$, supplemented with $5 \%$ fetal calf serum (FCS-25 $0.05 \mathrm{ml} / \mathrm{ml}), 1 \%$ antibiotics (10000 U Penicillin/ml, 10000 U Streptomycin $/ \mathrm{ml}$,gibco, Lot: $1697549)$ and amphotericin $\mathrm{B}(0.25 \mu \mathrm{g} / \mathrm{ml})$.

2. Store the tissue samples at $4{ }^{\circ} \mathrm{C}$.

\section{Isolation of Intimal Endothelial Cells}

1. Transfer the tissue sample (length, $8-15 \mathrm{~cm}$ ) into a petri dish. Remove all adherent sections on the outside surface of the aorta using surgical scissors. Wash the inner and outer surfaces of the aorta with saline and PBS buffer (Fig. 1a).

2. Fill aorta with PBS buffer containing collagenase D and clamp two sides of the aorta using forceps (Fig. 1b).

3. Transfer the PBS/collagenase D buffer-containing samples slowly into the incubator $\left(37^{\circ} \mathrm{C}, 5 \% \mathrm{CO} 2\right)$ for 20-30 minutes.

4. Rinse the inner section of the aorta with serum-free EGM-MV (PromoCell) and collect the released endothelial cells (ECs) in a petri dish (Fig. 2).

5. Repeat the isolation process (steps 2-4), several times.

\section{Human Aortic Endothelial Cell Culture}

1. Prepare the cell pellet from the released cells using centrifugation technique (2500 rpm, 7 minutes).

2. Resuspend and seed the cell pellet in serum-free EGM-MV.

3. Culture the isolated cells in the serum-EGM-MV medium in 12-well plates after separation of detached pieces.

4. Incubate the cells in endothelial cell culture in an incubator $\left(37^{\circ} \mathrm{C}, 5 \% \mathrm{CO} 2\right)$ and change daily the culture medium for one week (Fig. 3).
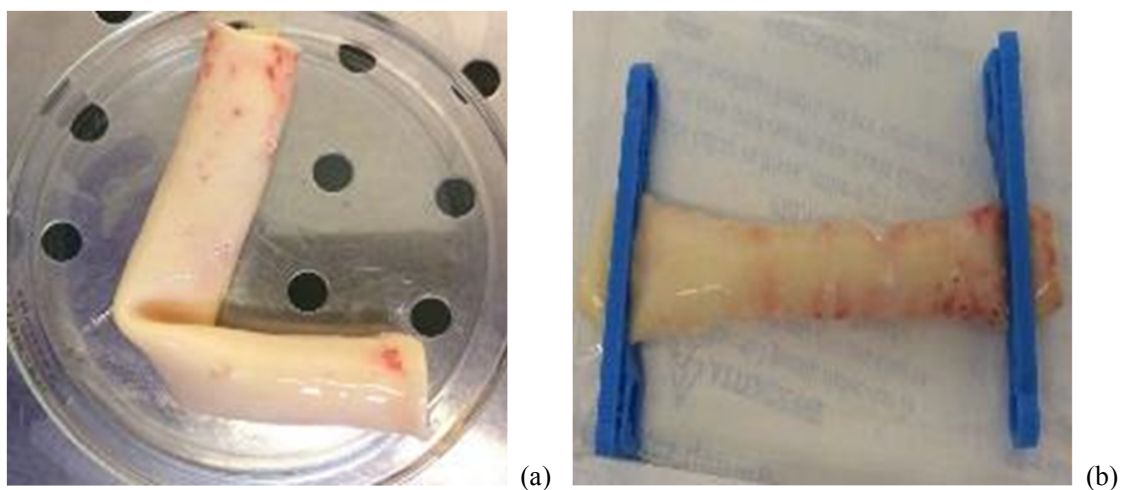

Fig. 1. (a) Human aortic sample. (b) The inner and outer surfaces of aorta cleaned up and clamped after filling with PBS/collagenase D buffer.

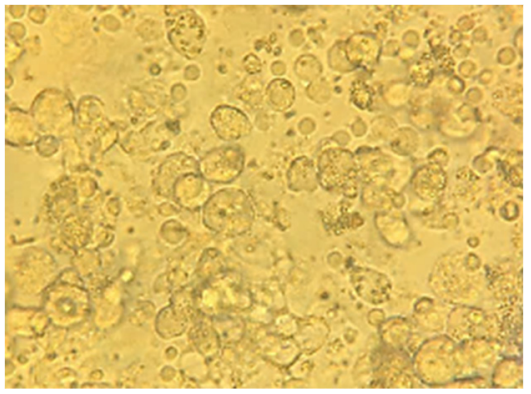

Fig. 2. Endothelial cells (ECs). The released endothelial cells (ECs) immediately after the incubation with collagenase D (day 0 ).

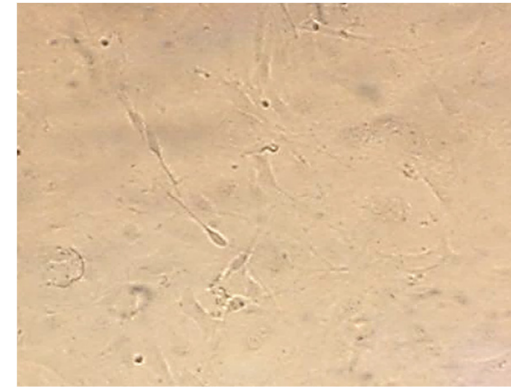

Fig. 3. Endothelial cells of the aorta (day 7). 
5. Detach the endothelial cells (ECs) by adding trypsin $\left(37{ }^{\circ} \mathrm{C}, 5 \% \mathrm{CO} 2,5\right.$ minutes) after 7 days and transfer the cells to $15 \mathrm{ml}$ falcon containing $10 \mathrm{ml}$ of endothelial cell culture medium (EGM-MV) and Fetal Calf Serum (10\%) to stop trypsin function.

6. Centrifuge (2500-3000 rpm, 6 minutes) and resediment with cold PBS (containing 10\% FBS).

7. Measure the expression of endothelial CD31 marker to confirm endothelial cells. For this purpose, wash the cells twice with cold PBS (5 min) and count the CD31+ cells using the AB applied biosystems Attune (Fig. 4).

\section{Histology}

1. Fix the pieces of intact and collagenase/PBS bufferexposed aortic tissues in PFA (10\%, 96 hours) according to the routine paraffin-embedding technique.

2. Prepare the tissue cross-sections perpendicular to the axis of blood flow (Fig. 5).

3. Stain routinely the thick paraffin sections (5-10 micrometers) by hematoxylin-eosin and evaluate the sections with invert microscope (Nikon Eclipse TE 2000$\mathrm{E}$ inverted microscope, 10x) before and after acting collagenase D.

\section{Isolated ECs and Leucocyte Adhesion}

1. Use CytoSelect тм Leukocyte-Endothelial Adhesion Assay kit (Cat. No.: CBA-210; CellBiolabs; Danmark) (9).

2. Add endothelial cells $(50,000-100,000)$ to gelatincoated 48-well plate.

3. Culture cells onto the coated substrate, where the adherent cells prepare a cellular monolayer after 48-72 hours.

4. Treat the endothelial monolayer with LPS (Cat. No.: L6529-1MG; Sigma Aldrich, Korea) ( $1 \mu \mathrm{g} / \mathrm{ml}, 6$ hours)

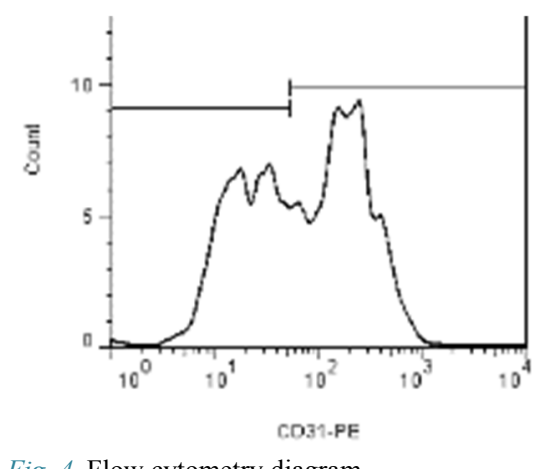

Fig. 4. Flow cytometry diagram

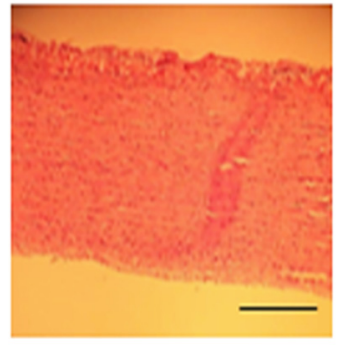

aorta pre digestion

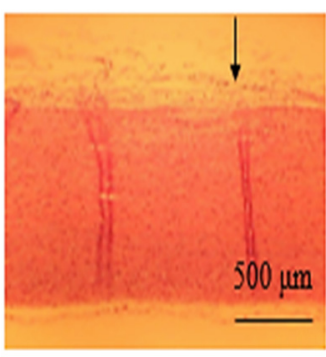

aorta post digestion
(10) on the seventh day of EC culture.

5. Isolate the human monocytes using RosetteSep kit (Stem cell Technologies), an immunodensity technique for the isolation of monocytes from fresh whole blood (11).

5.1. Incubate the falcon containing whole blood sample $(5 \mathrm{ml})$ and RosetteSep ${ }^{\mathrm{TM}}$ Enrichment Cocktail for 20 minutes.

5.2. Add an equal volume of FBS (\%2)/PBS to the blood sample and mix gently.

5.3. Centrifuge (2500 rpm, 20 minutes).

5.4. Wash enriched cells with FBS (\%2)/PBS after removing the medium layer.

5.5. Make a monocyte suspension $(0.5-1.0 \times 106 / \mathrm{ml})$ in serum-free media and add LeukoTracker for preparation of final concentration of $1 \mathrm{X}$.

6 . Incubate $\left(37^{\circ} \mathrm{C}, 60\right.$ minutes $)$, centrifuge ( $1000 \mathrm{rpm}, 2$ minutes), aspirate the medium, wash pellet and resuspend it in a serum-free media.

7. Wash pellet with the serum-free media after elimination of supernatant. Then, transfer the monocyte solution containing LeukoTracker $(200 \mu \mathrm{L})$ to the endothelial monolayer-containing wells and incubate for 30-90 minutes.

8. Carefully aspirate the media from each well and wash each well (3 times) with Wash buffer $(250 \mu \mathrm{L})$ to remove the unbound cells.

9. Aspirate the final wash solution and add Lysis buffer $(150 \mu \mathrm{L})$ to each well. Incubate at room temperature with shaking for 5 minutes.

10. Transfer $100 \mu \mathrm{L}$ of the final mixture to each well of the 96-well plate for fluorescence analysis (SpectraMax Gemini XS Fluorometer, 485/538 nm filter) (Fig. 6).

\section{Discussion}

Atherosclerosis is associated with molecular and cellular events in arteries $(12,13)$. In the present study, a method is described for the isolation of endothelial cells from the human aorta and their functions in the adhesion process. Most methods used for primary EC isolation are involved with the enzyme digestion by a collagenase solution to detach the ECs from the basement membrane of large vessels (14). However, costly techniques are applied often for small vessels following an appropriate culture medium (15). Oosterhoff et al. suggested a combined en-

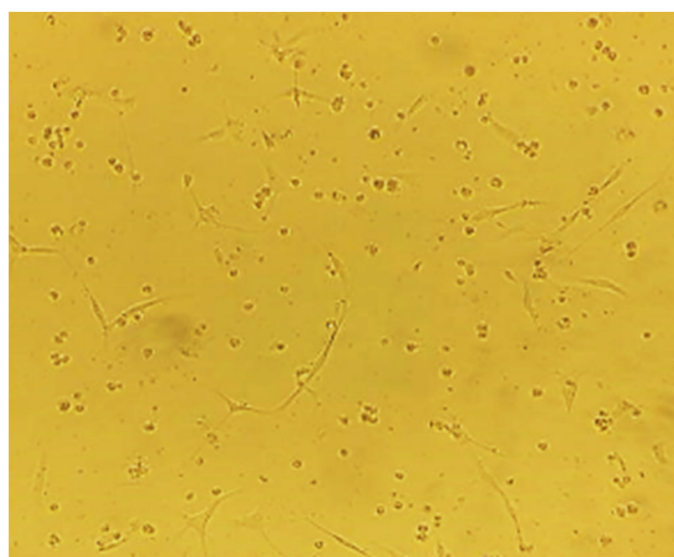

Fig. 6. LeukoTracker ${ }^{\mathrm{TM}}$ labeled THP-1 human monocyte cells adhered to endothelial monolayer $(\times 20$ magnification $)$. 
dothelial cell isolation technique, containing the inversion of the small vessels and floating them in enzyme solution that may lead to cellular contamination (16). These techniques require validation on considering the heterogeneity of EC intravascular population (17) and the possibility of changing the expression of cell surface markers in the pathologic states $(18,19)$. The technique suggested for the isolation of aortic primary endothelial cells in this paper may be used for human macrovascular tissues. The technique is based on the collagenase digestion restriction of vessel's exterior surface. The procedure is able to isolate endothelial cells with higher purity and at least contamination. Other antibody-based techniques, however, might improve the cellular purity but they are time-consuming and expensive. There are some quality control techniques to guarantee the method reliability such as the transendothelial resistance that may be identified by the measurement of anti-CD31 or anti-von Willebrand factor (vWF). In this study, the anti-CD31 level was measured in the isolated endothelial cells.

There are some recommendations on the method troubleshooting;

i. The need to a sterile working area.

ii. The use of a fresh tissue samples.

iii. The evaluation of enzyme quality.

iv. The use of amphotericin B.

\section{Conclusions/Significance}

The technique might be used for the isolation of endothelial cells from aortic segments. The isolated endothelial cells are able to prepare the proper primary cultures and provide a reliable source for investigating the processes of atherosclerosis and vessel restenosis.

\section{Acknowledgments}

The study protocol is part of a master's thesis that is supported by Iran University of Medical Sciences.

\section{Conflict of Interests}

The authors declare that they have no competing interests.

\section{References}

1. Bäck M, Gasser TC, Michel JB, Caligiuri G. Biomechanical factors in the biology of aortic wall and aortic valve diseases. Cardiovasc Res. 2013;99(2):232-41.

2. Skacel P, Bursa J. Comparison of constitutive models of arterial layers with distributed collagen fibre orientations. Acta Bioeng Biomech. 2014;16(3):47-58.

3. Halper J, Kjaer M. Basic components of connective tissues and extracellular matrix: elastin, fibrillin, fibulins, fibrinogen, fibronectin, laminin, tenascins and thrombospondins. Adv Exp Med Biol. 2014;802:31-47.

4. Pi X, Xie L, Patterson C. Emerging Roles of Vascular Endothelium in Metabolic Homeostasis. Circ Res. 2018;123(4):477-494.

5 Fukai T, Ushio-Fukai M. Superoxide dismutases: role in redox signaling, vascular function, and diseases. Antioxid Redox Signal. 2011;15(6):1583-606.

6. Wang D, Wang Z, Zhang L, Wang Y. Roles of Cells from the Arterial Vessel Wall in Atherosclerosis. Send to Mediators Inflamm. 2017:8135934.

7. Leclercq A, Veillat V, Loriot S, Spuul P, Madonna F, Roques X, Génot E. A Methodology for Concomitant Isolation of Intimal and
Adventitial Endothelial Cells from the Human Thoracic Aorta. PLoS One. 2015;10(11):e0143144.

8. Ataollahi F, Pingguan-Murphy B, Moradi A, Wan Abas WA, Chua $\mathrm{KH}$, Abu Osman NA. New method for the isolation of endothelial cells from large vessels. Cytotherapy. 2014;16(8):1145-52.

9. Manual, P., CytoSelect ${ }^{\mathrm{TM}}$ Leukocyte-Endothelium Adhesion Assay.

10. Park G, Kim J. LPS Up-Regulates ICAM-1 Expression in Breast Cancer Cells by Stimulating a MyD88-BLT2-ERK-Linked Cascade, Which Promotes Adhesion to Monocytes. Mol Cells. 2015;38(9): $821-828$.

11. Hassanpour P, Amirfarhangi A, Hosseini-Fard SR, Yarnazari A, Najafi M. Interleukin 6 may be related to indoleamine 2,3-dioxygense function in M2 macrophages treated with small dense LDL particles. Gene. 2017;626:442-446

12. Zhang L, Bhaloo S, Chen T, Zhou B, Xu Q. Role of Resident Stem Cells in Vessel Formation and Arteriosclerosis. Circ Res. 2018;122(11):1608-1624.

13. Galkina E, Ley K. Immune and inflammatory mechanisms of atherosclerosis. Annu Rev Immunol. 2009;27:165-97.

14. Hao Q,Chen X, Ma L, Wang T, Hu Y, Zhao Y. Procedure for the Isolation of Endothelial Cells from Human Cerebral Arteriovenous Malformation (cAVM) Tissues. Front Cell Neurosci. 2018;12:30.

15. Kovacs-Kàsa A, Varn M, Verin A, Gonzales J. Method for the Culture of Mouse Pulmonary Microvascular Endothelial Cells. Sci Pages Pulmonol. 2017;1(1):7-18.

16. Oosterhoff LA, Kruitwagen HS, Spee B, van Steenbeek FG. Isolation and Culture of Primary Endothelial Cells from Canine Arteries and Veins. J Vis Exp. 2016;(117).

17. Rakocevic J, Orlic D, Mitrovic-Ajtic O, Tomasevic M, Dobric M, Zlatic N, Milasinovic D, Stankovic G, Ostojić M, Labudovic-Borovic M. Endothelial cell markers from clinician's perspective. Exp Mol Pathol. 2017;102(2):303-313.

18. Helmke A, Casper J, Nordlohne J, David S, Haller H, Zeisberg E, von Vietinghoff S. Endothelial-to-mesenchymal transition shapes the atherosclerotic plaque and modulates macrophage function. The FASEB Journal, 2018: p. fj. 201801238R.

19. van Beijnum JR, Rousch M, Castermans K, van der Linden E, Griffioen AW. Isolation of endothelial cells from fresh tissues. Nat Protoc. 2008;3(6):1085-91. 